\title{
Comparison of the in vitro and in vivo susceptibilities of Burkholderia mallei to Ceftazidime and Levofloxacin
}

\author{
Barbara M Judy ${ }^{1}$, Gregory C Whitlock ${ }^{2,3}$, Alfredo G Torres ${ }^{2,4,5}$ and D \\ Mark Estes*1,2,5
}

\begin{abstract}
Address: ${ }^{1}$ Department of Pediatrics, University of Texas Medical Branch, Galveston, Texas, USA, ${ }^{2}$ Department of Microbiology and Immunology, University of Texas Medical Branch, Galveston, Texas, USA, ${ }^{3}$ Department of Clinical Laboratory Sciences, University of Texas Medical Branch, Galveston, Texas, USA, ${ }^{4}$ Department of Pathology, University of Texas Medical Branch, Galveston, Texas, USA and ${ }^{5}$ Sealy Center for Vaccine Development, University of Texas Medical Branch, Galveston, Texas

Email: Barbara M Judy - bmjudy@utmb.edu; Gregory C Whitlock - gcwhitlo@utmb.edu; Alfredo G Torres - altorres@utmb.edu; D Mark Estes*-dmestes@utmb.edu

* Corresponding author
\end{abstract}

Published: 9 May 2009

BMC Microbiology 2009, 9:88 doi:10.1 |86/147|-2180-9-88
Received: 2I October 2008

Accepted: 9 May 2009

This article is available from: http://www.biomedcentral.com/l47I-2180/9/88

(c) 2009 Judy et al; licensee BioMed Central Ltd.

This is an Open Access article distributed under the terms of the Creative Commons Attribution License (http://creativecommons.org/licenses/by/2.0), which permits unrestricted use, distribution, and reproduction in any medium, provided the original work is properly cited.

\begin{abstract}
Background: Burkholderia mallei is a zoonotic Gram negative bacterium which primarily infects solipeds but can cause lethal disease in humans if left untreated. The effect of two antibiotics with different modes of action on Burkholderia mallei strain ATCC23344 was investigated by using in vitro and in vivo studies.

Results: Determination of minimal inhibitory concentrations (MICs) in vitro was done by the agar diffusion method and the dilution method. The MICs of levofloxacin and ceftazidime were in the similar range, 2.5 and $5.0 \mu \mathrm{g} / \mathrm{ml}$, respectively. Intracellular susceptibility of the bacterium to these two antibiotics in J774A.I mouse macrophages in vitro was also investigated. Macrophages treated with antibiotics demonstrated uptake of the drugs and reduced bacterial loads in vitro. The efficacy of ceftazidime and levofloxacin were studied in BALB/c mice as post-exposure treatment following intranasal B. mallei infection. Intranasal infection with $5 \times 10^{5} \mathrm{CFUs}$ of $B$. mallei resulted in $90 \%$ death in non-treated control mice. Antibiotic treatments 10 days post-infection proved to be effective in vivo with all antibiotic treated mice surviving to day 34 post-infection. The antibiotics did not result in complete clearance of the bacterial infection and presence of the bacteria was found in lungs and spleens of the survivors, although bacterial burden recovered from levofloxacin treated animals appeared reduced compared to ceftazidime.
\end{abstract}

Conclusion: Both antibiotics demonstrated utility for the treatment of glanders, including the ability for intracellular penetration and clearance of organisms in vitro.

\section{Background}

Burkholderia mallei, the causative agent of glanders, a primary equine disease, is a Gram-negative, facultative intracellular bacterium which can be transmitted to humans with fatal consequences [1]. Human infections typically occur in people who have direct contact with glanderous animals such as veterinarians, farmers or laboratory workers. The most likely route of transmission involves contact of infectious exudates with cuts and abrasions or with mucosal membranes. $B$. mallei are also highly infectious 
organisms by aerosol and it is widely believed that it harbors the potential for use as a biological weapon [2]. In fact, the bacterium was one of the first agents used in biologic warfare during the American Civil War, World Wars I and II, and Russian invasion of Afghanistan. Consequently, it has been placed on the CDC category B agent list [3]. Inhalation of aerosol or dust containing B. mallei can lead to septicemia, pulmonary or chronic infections of the muscle, liver and spleen. The disease has a 95\% case fatality rate for untreated septicemia infections and a 50\% case fatality rate in antibiotic-treated individuals [4]. The ability of $B$. mallei to cause severe, rapidly fatal invasive infection initiated via aerosol in animals and humans, coupled with intrinsic resistance to antibiotics and diagnostic difficulty at early stage of disease make the bacterium a good candidate as a possible biological threat agent $[5,6]$. Our knowledge of pathogenesis of disease due to $B$. mallei is minimal. The disease was eliminated from domestic animals in the United States during the 1940s and the last reported naturally acquired human case in the United States occurred in 1945. There is little data available on antibiotic treatment of glanders and human cases are treated with the same regimens used for melioidosis, an endemic disease in Southeast of Asia and Northern Australia, caused by Burkholderia pseudomallei. Only one case of laboratory-acquired human glanders was reported to CDC recently [7]. This single human case of glanders corroborated in vitro data with in vivo efficacy for the $B$. mallei ATCC 23344 strain when a combination of intravenous doxycycline plus imipenem followed by oral doxycycline plus azithromycin successfully controlled a disseminated infection [7]. However, at present, the treatment of $B$. mallei with antibiotic therapy is still not well established and no effective vaccines are available.

Few in vitro antibiotic susceptibility studies for $B$. mallei have been performed. The antibiotic susceptibility of $B$. malle $i$ is similar to that of $B$. pseudomallei, with resistance to a number of antibiotics [8]. Both organisms appear to be sensitive to imipenem and doxycycline, while most strains are susceptible to ceftazidime, ciprofloxacin, and piperacilin [9]. Unfortunately clinical experience with $B$. pseudomallei infections has shown that despite good in vitro activity, an antibiotic may be ineffective in vivo $[10,11]$. We chose ceftazidime, highly recommended drug for treatment of melioidosis. Ceftazidime belongs to the beta-lactam group, a broad spectrum antibiotic, structurally and pharmacologically related to penicillins, which work by inhibiting the bacterial cell wall synthesis. This third generation cephalosporin is effective against Pseudomonas and other Gram-negative bacteria. The second antibiotic chosen, levofloxacin, belongs to the quinolone group which inhibits the bacterial DNA gyrase in Gramnegative bacteria, thereby inhibiting DNA replication and transcription. Quinolones can enter cells easily and therefore are often used to treat intracellular pathogens. As there is a need for effective treatment and post-exposure prophylaxis, the objective of this study was to assess the in vitro susceptibilities of these antibiotics with different modes of action and compare with efficacy in macrophages and mice infected with $B$. mallei.

\section{Results}

\section{Susceptibility testing, MIC determination}

MICs were determined by the agar diffusion method and dilution method. The results from the agar diffusion method are listed in Tables 1 and 2. Our results indicate that B. mallei strain ATCC 23344 is susceptible to a concentration as low as $10 \mu \mathrm{g} / \mathrm{ml}$ of ceftazidime and $25 \mu \mathrm{g} / \mathrm{ml}$ of levofloxacin comparable to our E. coli control strain. The MICs were further evaluated by the dilution method for confirmation, resulting in $5 \mu \mathrm{g} / \mathrm{ml}$ of ceftazidime or $2.5 \mu \mathrm{g} / \mathrm{ml}$ of levofloxacin sufficient to inhibit the growth of $B$. mallei in LBG after $18-24 \mathrm{~h}$ incubation at $37^{\circ} \mathrm{C}$ under shaking conditions.

\section{In vivo post-exposure prophylaxis with levofloxacin and ceftazidime}

The confirmed challenge dose of B. mallei was $4.7 \times 10^{5}$ CFU per animal delivered i.n. in $50 \mu \mathrm{l}$ PBS $(25 \mu \mathrm{l}$ per nare). Non-treated control animals became sick within 48 $\mathrm{h}$ post-challenge indicated by non-specific signs such as piloerection and hypo-activity with trembling. The infection progressed with first deaths observed by day 4 postchallenge (Fig. 1). By day 6, 80\% of non-treated control animals were dead with only one survivor in this group by

Table I: Inhibition zone size standards for B. mallei for ceftazidime disks

\begin{tabular}{lcl}
\hline \multicolumn{1}{r}{ Disk potency $(\mathrm{mg} / \mathrm{ml})$} & Zone diameter $(\mathrm{mm})$ for B. mallei ATCC23344 & Pattern of resistance/suceptibility \\
\hline 10 & $>32$ & Susceptible \\
1 & $>32$ & Susceptible \\
$1 \times 10^{-1}$ & 32 & Susceptible \\
$1 \times 10^{-2}$ & 30 & Susceptible \\
$1 \times 10^{-3}$ & 19 & Intermediate \\
$1 \times 10^{-4}$ & $<1$ & Resistant \\
$1 \times 10^{-5}$ & $<1$ & Resistant \\
$1 \times 10^{-6}$ & $<1$ & Resistant \\
\hline
\end{tabular}


Table 2: Inhibition zone size standards for B. mallei for levofloxacin disks

\begin{tabular}{|c|c|c|}
\hline Disk potency $(\mathrm{mg} / \mathrm{ml})$ & Zone diameter $(\mathrm{mm})$ for B. mallei ATCC23344 & Pattern of resistance/susceptibility \\
\hline 2.5 & $>40$ & Susceptible \\
\hline $2.5 \times 10^{-1}$ & $>40$ & Susceptible \\
\hline $2.5 \times 10^{-2}$ & 27 & Susceptible \\
\hline $2.5 \times 10^{-3}$ & 10 & Intermediatee \\
\hline $2.5 \times 10^{-4}$ & $<1$ & Resistant \\
\hline $2.5 \times 10^{-5}$ & $<1$ & Resistant \\
\hline $2.5 \times 10^{-6}$ & $<1$ & Resistant \\
\hline $2.5 \times 10^{-7}$ & $<1$ & Resistant \\
\hline
\end{tabular}

day 34 (which lacked severe signs consistent with disease). Ceftazidime and levofloxacin, administrated i.p. 24 hours post-challenge, once a day, for 10 days, significantly reduced signs of the disease and proved to be effective with $100 \%$ survival rates at day $34(\mathrm{P}<0.0001)$ on both treatments. Histological examination of organs from antibiotic treated survivors showed highly enlarged spleens with large, multifocal abscesses with extension into abdominal muscles in all infected animals (data not shown). The spleens of both antibiotic treated and nontreated animals exhibited a $6-10$ fold increase in weight compared to uninfected healthy animals. Both spleens and livers showed myeloid hyperplasia. Interestingly, no

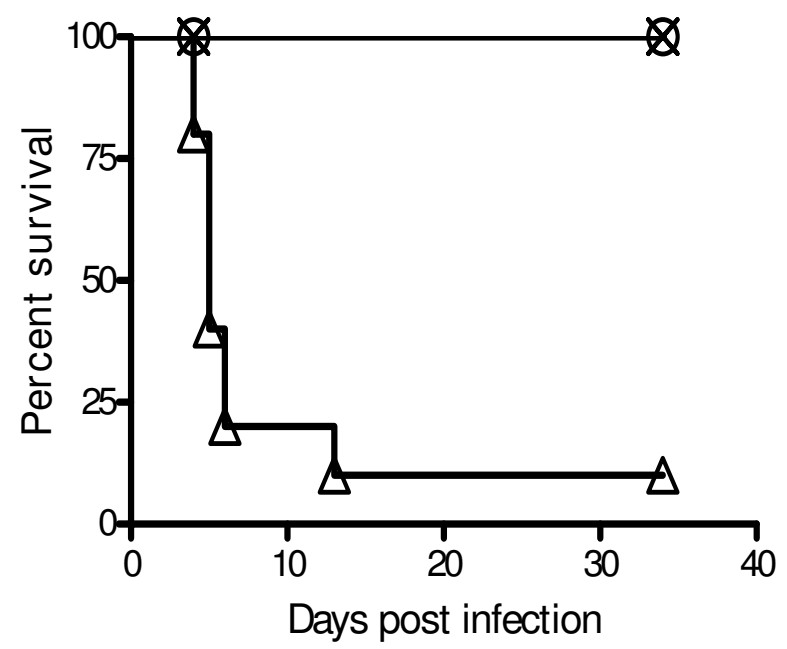

Figure I

Percentage of survival of BALB/c mice challenged with $5 \times 10^{5}$ CFUs of B. mallei intranasally $(n=10)$. Treatment with antibiotic started 24 hours post-infection, once a day, for 10 days. Ceftazidime $(\mathbf{X})$ and levofloxacin (m) were administrated i.p. in doses $100 \mathrm{mg} / \mathrm{kg} /$ day and $20 \mathrm{mg} / \mathrm{kg} /$ day respectively. The infection of $B$. mallei resulted in $90 \%$ death in non-treated animals (\&\#x25B3;). All antibiotic treated mice survived to day 34 post-infection. Experiment performed twice, $P<0.000$ I for non-treated vs. antibiotic treated animals. lesions were found in the lungs of animals (data not shown).

\section{Bacterial load at day $\mathbf{3 4}$ post-infection}

Harvested lungs and spleens from each group of animals challenged with $5 \times 10^{5} \mathrm{CFU} / 50 \mu \mathrm{l}$ by i.n. route were subjected to plating on LBG for CFU determination per gram of organ weight. One animal from levofloxacin treatment was free of bacteria in spleen and liver. The spleen from this animal looked normal, was not enlarged, suggesting that in this particular case, infection was not effective. Bacterial counts in the spleens from remaining antibiotic treated animals were similar, $1.9 \times 10^{4} \pm 3.9 \times 10^{3} \mathrm{CFU} / \mathrm{g}$ for ceftazidime and $1.2 \times 10^{4} \pm 6.6 \times 10^{3} \mathrm{CFU} / \mathrm{g}$ for levofloxacin and significantly lower from non-treated control animals $\left(1.8 \times 10^{7} \pm 8.6 \times 10^{6} \mathrm{CFU} / \mathrm{g}\right.$ of spleen, Fig. 2$)$. By day 34 post-infection, bacteria was largely cleared from the lungs with no significant differences between antibi-

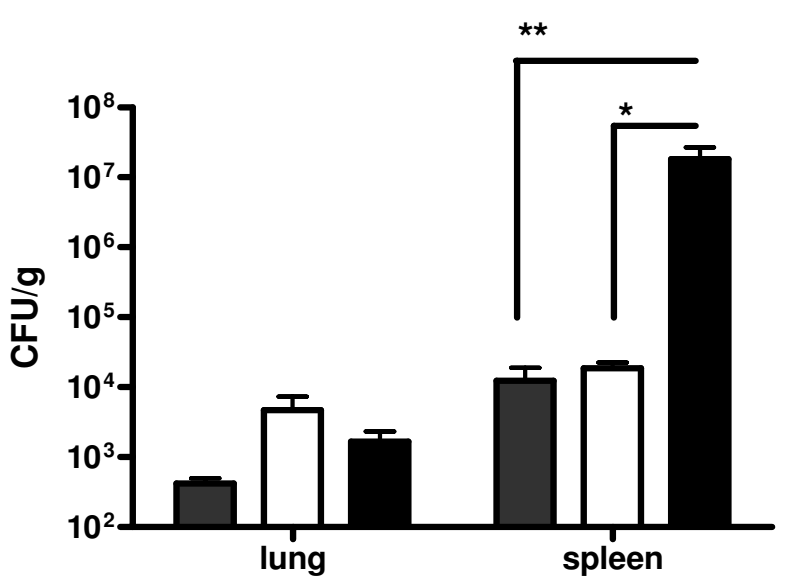

Figure 2

Reduced B. mallei bacterial burden in antibiotic treated BALB/c mice. Thirty-four days post-challenge, surviving levofloxacin treated mice (black bars), ceftazidime treated mice (white bars) and untreated control mice (crossed bars) were euthanized, and lungs and spleens were harvested, weighed and serial dilutions plated for CFU/g tissue weight., $* \mathrm{P}<0.05$, $* * \mathrm{P}<0.01$. Errors bars represent mean \pm SEM. 
otic treated and non-treated animals, although bacterial burden of the spleens suggested that all animals developed chronic infection with $B$. mallei.

\section{The efficacy of ceftazidime and levofloxacin to kill intracellular bacteria in vitro}

For the determination of intracellular killing of $B$. mallei by antibiotics of interest, we performed a bacterial uptake assay by murine macrophages J774A.1 and evaluated bacterial killing for 8 hours of continuous exposure to antibiotics in concentrations equal to $100 \times$ MIC for each compound tested. Murine J774A.1 cells were infected at an MOI of 25:1 and incubated for 2 hours in the absence of any antibiotics to allow for uptake (Time 0 ). At two hour intervals post-antibiotic exposure, intracellular CFU were determined resulting in a significant reduction of intracellular bacteria which continued throughout the assay (Fig. 3). Media in control wells contained $250 \mu \mathrm{g} / \mathrm{ml}$ kanamycin for first $2 \mathrm{~h}$ postinfection and $100 \mu \mathrm{g} / \mathrm{ml} \mathrm{kan-}$ amycin for the rest of the assay to prevent the growth of extracellular bacteria[12,13]. Media was free of bacteria throughout the entire experiment, suggesting efficient killing of extracellular bacteria (data not shown). At the

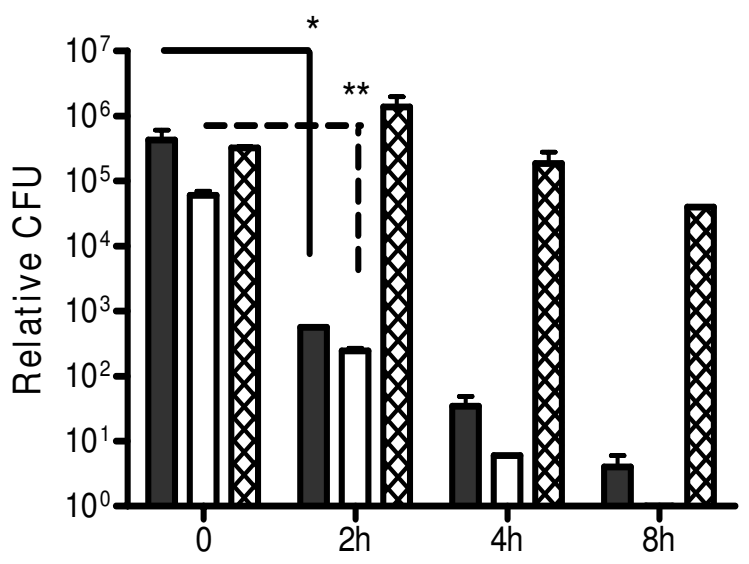

Figure 3

Antibiotic mediated intracellular killing of $B$. mallei infected J774A.I murine macrophages. Bacteria were added at an $\mathrm{MOI}$ of $25: \mathrm{I}$ and incubated for 2 hours at $37^{\circ} \mathrm{C}$ with $5 \% \mathrm{CO}_{2}$ followed by incubation with $100 \times$ MIC levofloxacin (black bars), ceftazidime (white bars) or media only (crossed bars). Media in control wells contained $250 \mu \mathrm{g} / \mathrm{ml}$ kanamycin for first $2 \mathrm{~h}$ postinfection and $100 \mu \mathrm{g} / \mathrm{ml}$ kanamycin for the rest of the assay to prevent the growth of extracellular bacteria. At 2, 4 and $8 \mathrm{~h}$ post treatment, cells were washed and lysed with $0.1 \%$ Triton $X-100$, followed by serial 10 -fold dilutions plated on LBG plates and incubated at $37^{\circ} \mathrm{C}$ for 2 days for CFUs determination. Experiment performed twice in triplicate. Errors bars represent mean \pm SEM. $* \mathrm{P}<$ 0.05 significant difference between time 0 and all time points in levofloxacin treatment, $* * P<0.01$ significant difference between time 0 and all time points in ceftazidime treatment. end of experiment, after 8 hours post-exposure to antibiotics, intracellular B. mallei CFUs were negligible from cell lysates. Similar results were obtained with lower antibiotics concentration $10 \times$ MIC and lower MOI, 12:1 (data not shown). The lactate dehydrogenase (LDH) cytotoxicity assay was performed during bacterial invasion assays to monitor cytotoxic effects of bacteria on J774A.1 macrophages. Throughout the assay LDH levels were below $20 \%$. Cytotoxicity was observed at $8 \mathrm{~h}$ in ceftazidime treated macrophages, reaching $25.7 \%$ which may have contributed to the decrease in recoverable intracellular bacteria in this treatment. Possible cytotoxic effects of antibiotics alone was tested in separate experiments for up to $24 \mathrm{~h}$, including concentrations higher than that tested, showing no significant LDH levels (data not shown).

\section{Discussion}

Limited data of in vitro antibiotic susceptibilities to strains of $B$. mallei has been published. The recommendations for treatments of glanders are largely based on knowledge of pathogenesis of melioidosis, a human disease caused by a closely related species $B$. pseudomallei. Currently, ceftazidime is the first antibiotic of choice for treatment of acute melioidosis [14]. The previously established MICs of 16 different antimicrobials evaluated against both species showed most strains susceptible to ceftazidime, ciprofloxacin, imipenem, and doxycycline [8]. Although $B$. malle $i$ has a susceptibility profile similar to B. pseudomallei, the MICs are usually lower in case of B. mallei [15]. Due to emergence of resistant strains and cases of disparity between in vitro susceptibility and clinical outcome of the treatments for melioidosis, the development of effective treatments has been difficult $[10,16,17]$. Both species, $B$. mallei and B. pseudomallei, share morphological, biochemical and antigenic characteristics, and could be expected that similar problems will occur in the case of B. mallei. There is a need for an extensive evaluation of susceptibility of antibiotics to these pathogens beyond in vitro studies.

Animal models to study equine glanders have been established [18] while there is a general lack of infection models that mimic human infection. Among rodents, guinea pigs and hamsters are most susceptible to glanders [19]. Mice, on the other hand, have similar resistance to glanders infections as humans, which makes this model more suitable to study therapies for $B$. mallei. Only intraperitoneal pathogenesis of glanders has been well described in the mouse model [20] with more recent studies of the bacterium administered via the aerosol or intranasal routes [21].

Here, we evaluated the susceptibilities in vitro of B. mallei to ceftazidime and levofloxacin, and their efficacy in vivo using intranasal infection in BALB/C mice, as inhalation 
would be the most likely route of infection in the event of bioterrorism threat. In previous in vitro studies, ceftazidime proved to be effective against $B$. mallei among others including imipenem, doxycycline, piperacillin, ciprofloxacin $[8,9]$. Levofloxacin demonstrates relatively high levels of activity against $B$. mallei but not $B$. pseudomallei [22]. Levofloxacin is known to achieve higher intracellular concentration and is recommended for intracellular infections [23]. Our results indicate that B. mallei strain ATCC 23344 is susceptible to a concentration as low as $2.5 \mu \mathrm{g} /$ $\mathrm{ml}$ of levofloxacin and $5 \mu \mathrm{g} / \mathrm{ml}$ of ceftazidime. These results confirmed prior studies evaluating susceptibility of 15 isolates of $B$. mallei to 35 antimicrobial agents [15]. In this study, ceftazidime and levofloxacin appeared in the group of most effective drugs tested in this panel against B. mallei. However, the high percentage of resistant strains of $B$. pseudomallei to levofloxacin and the emergence of ceftazidime-resistant clinical isolates of $B$. pseudomallei would affect the recommendations of these drugs as useful treatment for both glanders and melioidosis, underlining the need for supplementary monitoring of the effectiveness of the recommended antimicrobials.

The effectiveness of levofloxacin and ceftazidime in vitro were substantiated in our in vivo experiments with all treated mice surviving at least 34 days post infection. The intranasal infection of mice with $5 \times 10^{5} \mathrm{CFUs}$ of $B$. mallei resulted in $90 \%$ death in untreated control mice. Treatment with antibiotics used in this study prevented the development of an acute lethal form of disease but lacked the ability to provide complete clearance of the bacterial infection. By 34 days post-infection, bacteria were largely cleared from the lungs with no significant differences between treatments. Interestingly, in our intranasal infection model, the spleen appears to be the major target tissue for glanders infection and a site of multifocal abscesses. Similar findings were documented in studies with intraperitoneal glanders in mice and hamsters $[20,24]$. The untreated and antibiotic-treated mice exhibited a 6-10 fold increase in spleen weights compared to healthy, uninfected animals. Bacterial loads in spleens were significantly reduced in antibiotic treated animals compared to untreated control but remained in the range of $1.6 \times 10^{4} \mathrm{CFU} / \mathrm{g}$ of spleen. The antibiotics administrated 24 hours post-infection for 10 days led to the development of a chronic, non-lethal abscess infection suggesting that $B$. mallei may have the propensity for latency, as does the very closely related organism $B$. pseudomallei [25]. Efficacy of other antibiotics tested in hamsters revealed that time of administration of antimicrobials is the important factor affecting protection against B. mallei [24]. The experiments showed that administration of treatment less than $24 \mathrm{~h}$ post-exposure resulted in protection against the pathogen. A similar conclusion was obtained in antibiotics efficacy testing against
B. pseudomallei infected mice [26]. Combined, this suggests that the infection could be contained or eliminated if very early antibiotic treatment was initiated to prevent the bacterial load from reaching a lethal dose in the host. The pharmacokinetics of each antimicrobial, relative to the in vitro MIC and the ability of the bacteria to reside in privileged intracellular sites (not always easily accessible to the antimicrobials) should be considered as an important factor in effective treatment. For that reason, we tested levofloxacin in our study since fluoroquinolones are known to penetrate renal, lung and bronchial track tissues achieving a high intracellular concentration exceeding levels of the drug in serum [23]. Both antimicrobials were very effective in intracellular bacterial killing reducing bacterial loads to practically undetectable levels, validating their ability as cell-permeable antibiotics.

\section{Conclusion}

The current study showed that both ceftazidime and levofloxacin, despite good activity in vitro against B. mallei, failed to eradicate bacterium and resulted in development of a chronic, non-lethal form of glanders. Both antibiotics demonstrated some utility for treatment of glanders, including the ability for intracellular penetration and clearance of organisms in vitro, despite bacterial burdens recovered in vivo following i.p. antibiotic treatment.

\section{Methods \\ Bacterial strain}

B. mallei strain ATCC 23344 (China 7) was cultured on Luria-Bertani supplemented with $4 \%$ glycerol (LBG) agar plates for $48 \mathrm{~h}$ at $37^{\circ} \mathrm{C}$. Isolated colonies were sub-cultured to LBG broth, and cultures were incubated at $37^{\circ} \mathrm{C}$ until optical density readings at $600 \mathrm{~nm}\left(\mathrm{OD}_{600}\right)$ reached an exponential phase of growth. Bacteria were pelleted by centrifugation, washed and re-suspended in sterile $1 \times$ phosphate-buffered saline (PBS, $\mathrm{pH}$ 7.4) to obtain the desired $\mathrm{CFU} / \mathrm{ml}$. All procedures were performed in a biosafety level 3 laboratory.

\section{Antimicrobial susceptibility testing (MIC determination)}

The minimal inhibitory concentrations of the antibiotics were tested by the Kirby-Bauer disk diffusion method and the dilution method as previously described (Clinical and Laboratory Standards Institute, formerly NCCLS. 20003. Performance standards for antimicrobial disk susceptibility tests. 309 Approved standard - Eighth Edition M2-A8, ISBN 1-56238-485-6, CLSI. Wayne, Pa.). Briefly, fresh antibiotic-containing disks (serial dilutions) were used for susceptibility testing. LBG plates were inoculated with $B$. mallei ATCC 23344 and disks containing the antibiotic dilutions placed on top of the inoculated agar. The plates were incubated at $37^{\circ} \mathrm{C}$ for $24-48 \mathrm{~h}$. Zones were measured and the mean diameter was calculated. The interpretation of results was based on the NCCLS zone diameters 
used for non-Enterobacteriaceae. For the broth dilution method, an inoculum of $10^{5} \mathrm{CFU}$ of washed $B$. mallei per $\mathrm{ml}$ was used, and the test was conducted in LBG for $24 \mathrm{~h}$ at $37^{\circ} \mathrm{C}$. The interpretation of results was based on the NCCLS MIC breakpoints for non-Enterobacteriaceae and MIC for B. pseudomallei [16]. The inhibition of growth was confirmed by spectrophotometrically measurements and plating of serial dilutions onto LBG plates. Tubes containing bacteria but not antibiotic were included as a positive growth control.

\section{Mice}

Animal studies were carried out in accordance with the Animal Care and Use Committee's guidelines as recommended by the National Institutes of Health. Female, 6- to 8-week-old, BALB/c mice were obtained from Harlan Sprague Dawley, Inc. (Indianapolis, Indiana). Animals were provided with rodent feed and water ad libitum and maintained on $12 \mathrm{~h}$ light cycle.

Challenge with B. mallei and antimicrobial administration Groups of 10 animals were inoculated via intranasal (i.n.) route with $5 \times 10^{5}$ CFUs of $B$. mallei ATCC 23344, in a total volume of $50 \mu \mathrm{l}$ in PBS solution given to both nares. Treatment with antibiotic via intraperitoneal route (i.p.) started 24 hours after infection, once a day, for 10 days. Doses of antibiotics used in this study were in the range of high doses used in humans: ceftazidime $100 \mathrm{mg} / \mathrm{kg} /$ day and levofloxacin $20 \mathrm{mg} / \mathrm{kg} / \mathrm{day}$. The animals were weighed prior to challenge and doses of antibiotics were adjusted accordingly. Levofloxacin (Levaquin Injection, GlaxoSmithKline) and ceftazidime (Fortaz, OrthoMcNeil, Inc.) were purchased through local UTMB Pharmacy and doses for injection were prepared and stored according to manufacturer's instructions.

\section{Bacterial load determinations}

Five animals from each group of antibiotic treated animals and survivors from non-treated control animals, were sacrificed and lungs and spleen were harvested for CFU determination. Organs were weighed, homogenized in $5 \mathrm{ml}$ sterile PBS, plated in duplicates on LBG and incubated at $37^{\circ} \mathrm{C}$ for 2 days prior to CFU determinations. For comparison, spleen weights from healthy non infected but antibiotic treated animals were also evaluated. CFU were expressed as the mean \pm SEM. Organs (lung, spleen and liver) from additional remaining survivors were used for histological examinations.

\section{B. mallei J774A. I uptake and killing assays}

Murine J774A. 1 cells were seeded $\left(5 \times 10^{5}\right)$ onto Corning Costar 24 well plates (Corning, NY) with DMEM and incubated overnight at $37^{\circ} \mathrm{C}$ with $5 \% \mathrm{CO}_{2}$. Bacteria were added at an MOI of 25:1 to J774A. 1 cells in duplicate. The high MOI was used to guaranty that every macrophage was able to take up a large number of bacteria that survived the phagocytic activity of the cell but were killed by our experimental antibiotic treatment. Inoculated wells were centrifuged at $800 \times \mathrm{g}$ for 2 minutes and incubated for 2 hours at $37^{\circ} \mathrm{C}$ with $5 \% \mathrm{CO}_{2}$ followed by a PBS wash $(\times 3)$ and 2, 4 and 8 hours incubation with antibiotics. Media in control wells contained $250 \mu \mathrm{g} / \mathrm{ml}$ kanamycin for first $2 \mathrm{~h}$ postinfection and $100 \mu \mathrm{g} / \mathrm{ml}$ kanamycin for the rest of the assay to prevent the growth of extracellular bacteria $[12,13]$. The concentration of antibiotics tested in this assay was equal to $100 \times$ MIC for each compound. At appropriate time after incubation, cells were washed twice with PBS and lysed with $0.1 \%$ Triton X-100, followed by 10 -fold serial dilutions plated on LBG plates and incubated at $37^{\circ} \mathrm{C}$ for 2 days prior to colony forming units determination. Additionally, to monitor the J774A.1 cells during experiment, LDH (lactate dehydrogenase) cytotoxicity assay was performed according to manufacturer's instruction (BioVision Research Products, Mountain View, CA) at all time points.

\section{Statistical analysis}

Survival curves were calculated by Kaplan Meier survival analysis with log-rank tests between groups using GraphPad Prism (V.4.03 for windows). Comparisons of spleen weights were performed using ANOVA and LOG transformed values of bacterial load was analyzed by Student's t-test. P value $\leq 0.05$ was considered significant.

\section{Abbreviations}

MICs: Minimal inhibitory concentrations; i.p.: intraperitoneal; i.n.: intranasal.

\section{Authors' contributions}

BMJ designed and conducted experiments and drafted the manuscript. GCW contributed to design and conduct of experiments and drafting manuscript, AGT conducted and provided analysis of the bacterial work, DME conceived the study, participated in its design and coordination and helped to draft the manuscript. All authors read and approved the final manuscript.

\section{Acknowledgements}

This work was supported by contract from the National Institute of Allergy and Infectious Diseases NOI-Al-30065 (D.M.E. and A.G.T) and a fellowship award to G.C.W. from the Sealy Center for Vaccine Development. We thank Dr. Mark McArthur for sharing his expertise in area of histopathology.

\section{References}

I. Whitlock GC, Estes DM, Torres AG: Glanders: off to the races with Burkholderia mallei. FEMS Microbiol Lett 2007, 277(2): I I $5-122$.

2. Horn JK: Bacterial agents used for bioterrorism. Surg Infect (Larchmt) 2003, 4(3):28I-287.

3. Wheelis M: First shots fired in biological warfare. Nature 1998 , 395(6699):2। 3 . 
4. Mandell GB, J Dolin R: Pseudomonas species (including melioidosis and glanders). In Principles and practices of infectious disease 4th edition. Edited by: Mandell GBJ, Dolin R. New York: Churchill Livingstone; 1995:2006-2007.

5. Rotz LD, Khan AS, Lillibridge SR, Ostroff SM, Hughes JM: Public health assessment of potential biological terrorism agents. Emerg Infect Dis 2002, 8(2):225-230.

6. Voskuhl GW, Cornea P, Bronze MS, Greenfield RA: Other bacterial diseases as a potential consequence of bioterrorism: $Q$ fever, brucellosis, glanders, and melioidosis. J Okla State Med Assoc 2003, 96(5):214-217.

7. CDC: Laboratory-acquired human glanders. $49 \mathrm{MMWr}: \mathrm{CDC}$; 2000:532-535.

8. Kenny DJ, Russell P, Rogers D, Eley SM, Titball RW: In vitro susceptibilities of Burkholderia mallei in comparison to those of other pathogenic Burkholderia spp. Antimicrob Agents Chemother 1999, 43(I I):2773-2775.

9. Heine HS, England MJ, Waag DM, Byrne WR: In vitro antibiotic susceptibilities of Burkholderia mallei (causative agent of glanders) determined by broth microdilution and E-test. Antimicrob Agents Chemother 200I, 45(7):2II9-2I 2 I.

10. Dance DA, Wuthiekanun V, Chaowagul W, White NJ: The antimicrobial susceptibility of Pseudomonas pseudomallei. Emergence of resistance in vitro and during treatment. J Antimicrob Chemother 1989, 24(3):295-309.

II. Chaowagul W, Suputtamongkul Y, Smith MD, White NJ: Oral fluoroquinolones for maintenance treatment of melioidosis. Trans $R$ Soc Trop Med Hyg 1997, 9 I(5):599-60I.

12. Whitlock GC, Estes DM, Young GM, Young B, Torres AG: Construction of a reporter system to study Burkholderia mallei type III secretion and identification of the BopA effector protein function in intracellular survival. Trans $R$ Soc Trop Med Hyg 2008, 102(SuppI I):SI27-133.

13. Ribot W], Ulrich RL: The animal pathogen-like type III secretion system is required for the intracellular survival of Burkholderia mallei within $\mathbf{J 7 4 . 2}$ macrophages. Infect Immun 2006, 74(7):4349-4353.

14. White NJ, Dance DA, Chaowagul W, Wattanagoon Y, Wuthiekanun $\mathrm{V}$, Pitakwatchara N: Halving of mortality of severe melioidosis by ceftazidime. Lancet 1989, 2(8665):697-70I.

15. Thibault FM, Hernandez E, Vidal DR, Girardet M, Cavallo JD: Antibiotic susceptibility of 65 isolates of Burkholderia pseudomallei and Burkholderia mallei to $\mathbf{3 5}$ antimicrobial agents. J Antimicrob Chemother 2004, 54(6): I I34- I I 38.

16. Inglis T], Rodrigues F, Rigby P, Norton R, Currie BJ: Comparison of the susceptibilities of Burkholderia pseudomallei to meropenem and ceftazidime by conventional and intracellular methods. Antimicrob Agents Chemother 2004, 48(8):2999-3005.

17. Karunakaran R, Puthucheary SD: Burkholderia pseudomallei: in vitro susceptibility to some new and old antimicrobials. Scand J Infect Dis 2007, 39( 10):858-86I.

18. Lopez J, Copps J, Wilhelmsen C, Moore R, Kubay J, St-Jacques M, Halayko S, Kranendonk C, Toback S, DeShazer D, et al: Characterization of experimental equine glanders. Microbes Infect 2003. 5(I2): I|25-I|3|.

19. Howe C: Glanders. In The Oxford medicine Edited by: $\mathrm{C} \mathrm{H}$. New York: Oxford University Press; 1949:185-201.

20. Fritz DL, Vogel P, Brown DR, Deshazer D, Waag DM: Mouse model of sublethal and lethal intraperitoneal glanders (Burkholderia mallei). Vet Pathol 2000, 37(6):626-636.

21. Ulrich RL, Amemiya K, Waag DM, Roy CJ, DeShazer D: Aerogenic vaccination with a Burkholderia mallei auxotroph protects against aerosol-initiated glanders in mice. Vaccine 2005, 23(16): 1986-1992.

22. Thibault FM, Valade E, Vidal DR: Identification and discrimination of Burkholderia pseudomallei, B. mallei, and B. thailandensis by real-time PCR targeting type III secretion system genes. J Clin Microbiol 2004, 42(I 2):587I-5874.

23. Ho PL, Cheung TK, Kinoshita R, Tse CW, Yuen KY, Chau PY: Activity of five fluoroquinolones against $7 \mathrm{I}$ isolates of Burkholderia pseudomallei. J Antimicrob Chemother 2002, 49(6): 1042-1044.

24. Russell P, Eley SM, Ellis J, Green M, Bell DL, Kenny DJ, Titball RW: Comparison of efficacy of ciprofloxacin and doxycycline against experimental melioidosis and glanders. J Antimicrob Chemother 2000, 45(6):8|3-8|8.
25. Harley VS, Dance DA, Tovey G, McCrossan MV, Drasar BS: An ultrastructural study of the phagocytosis of Burkholderia pseudomallei. Microbios 1998, 94(377):35-45.

26. Sivalingam SP, Sim SH, Jasper LC, Wang D, Liu Y, Ooi EE: Pre- and post-exposure prophylaxis of experimental Burkholderia pseudomallei infection with doxycycline, amoxicillin/clavulanic acid and co-trimoxazole. I Antimicrob Chemother 2008, 6I(3):674-678.
Publish with Biomed Central and every scientist can read your work free of charge

"BioMed Central will be the most significant development for disseminating the results of biomedical research in our lifetime. "

Sir Paul Nurse, Cancer Research UK

Your research papers will be:

- available free of charge to the entire biomedical community

- peer reviewed and published immediately upon acceptance

- cited in PubMed and archived on PubMed Central

- yours - you keep the copyright 